\title{
Barriers in Education of Children from Socially Disadvantaged Environment
}

D. Bachyncova Giertliova (Daniela Bachyncova Giertliova)

University of Health and Social Work of St. Elisabeth Bratislava, SK.

\section{E-mail address:}

giertliovadaniela@gmail.com

\section{Reprint address:}

University of Health and Social Work of St. Elisabeth Bratislava

Vysnokubinska 269/149

Dolny Kubin

Slovakia

Source: Clinical Social Work and Health Intervention

Volume: 12

Issue: 4

Pages: $69-73$

Cited references: 7

\section{Reviewers:}

Johnson Nzau Mavole

Catholic university of Eastern Africa, Nairobi, KE

Jirina Kafkova

MSF, Freetown, SL

\section{Keywords:}

Social disadvantage. Family. Poverty. Preschool education. Education.

\section{Publisher:}

International Society of Applied Preventive Medicine i-gap

CSWHI 2021; 12(4): 69 - 73; DOI: 10.22359/cswhi_12_4_08 CC Clinical Social Work and Health Intervention

\section{Abstract:}

The paper discusses and summarizes the knowledge in the field of education of socially disadvantaged children with an emphasis on the Roma ethnic group in Slovakia. It focuses on the issue of pre-primary education of these children and points to the specifics that have a negative impact on the adaptation to the school educational process. The paper addresses the risk aspects of poverty, social exclusion, child development and the need for early intervention for families with children. Furthermore, in the article we focus on the support of children at the community level and on possible forms of aid that can help to achieve a more favorable development of the overall Roma family within specific projects. We also deal with early care, which is very important for the bio-psycho-social development of children and youth. 
In the animal kingdom, a human being, as a biological entity, is a certain anomaly, an oddity. Not only because of the ability to think and speak abstractly, but also because it is born to the world as a biologically and mentally 'incomplete' being. It lives through its youngest years in a 'social incubator', in which with the help of other people, it gradually learns to overcome the thread to its natural and spiritual existence. Human company is the natural environment for every human individual, thanks to which it becomes a fullyfledged personality. Thus the company to which human offspring, a child, is born is a non-negligible fact.

Nowadays, the thesis stating that a human is a being formed by natural forces (heritability, innate talents, nutrition, natural environment, ...); social factors (family, school, broader social environment, culture, ...); upbringing (intentionally organized activity) is universally accepted. It follows that the character of the 'social incubator' in which a child lives and grows up which is usually a family and the closest company of people, significantly influences what a person as an individual will be like in relation to himself, others and the surrounding world.

Thus after birth every person is growing into a particular cultural environment which mediates certain characteristic attitudes, opinions, experiences and knowledge to her/him. Every society then creates its institutions to it, from those family and school play an irreplaceable role in our culture. They are transmitters of cultural content, moral order and system of values, which are necessary for the child to be able to fully participate in society and cultural conditions created by it in the future.

Law No. 245/2008 on raising and education of children (school law) and about changes and additions to some laws, $\S 2$, article p): "child from socially disadvantaged environment or student from socially disadvantaged environment [is considered] a child or a student living in an environment which according to social, familial, economical and cultural conditions insufficiently stimulates a child's or student's mental, voluntary, emotional qualities, does not support its socialization and does not provide a sufficient amount of impulses for personal development. It is about defining a child according to the characteristics of environment the child lives in."
With 19 million children living below the poverty line in the EU-27, lowering child poverty and supporting social integration is a key political sphere of the European Union. In political documents of the EU, the importance of measures specifically focused on the most disadvantaged regions and those the most threatened by poverty, as incomplete families, minorities and disabled people, are becoming more and more acknowledged. The Roma population is one of the biggest and the most socially disadvantaged ethnic minorities in the EU. There are 10 to 12 million Roma people scattered through the European continent concentrated mainly around central and eastern Europe. It concerns a relatively young population; in certain countries there is $50 \%$ of the Roma citizens that are younger than 18 years. But most of the Roma children live on the periphery of society, in poverty and excluded and their situation has been significantly worsened in many countries throughout the last two decades.

"In Slovakia, the Roma population is one of the most vulnerable social groups threatened by poverty and social exclusion. These groups are commonly referred to as marginalized Roma communities. Out of total 450,000 Roma people living in Slovakia, 250, 000 to 260,000 of them is socially endangered (marginalized). The highest concentration of socially excluded communities is recorded in eastern Slovakia and southern regions of central Slovakia. This part of the population is exposed to extreme poverty which is spread to other generations. $29 \%$ of registered settlements do not have electricity; $81 \%$ of them do not have sewerage system; gas is not present in $59 \%$ of the settlements; water pipeline is absent in $37 \%$ of the settlements; $20 \%$ of the settlements does not have blacktop driveway. Out of all the settlements; 149 of them are considered segregated which means that the settlements are located on the periphery or out of a municipality or town. Nearly $\square$ of the settlements in Roma settlement villages are illegal (primarily shacks, portakabins, non-residential buildings, but also houses). The highest ratio of illegal settlements (49\%) are settlements out of a municipality/town. The most common type of illegal settlement are shanties. They add up to $16 \%$ of all settlements and $14 \%$ of inhabitants of Roma settlements live in that type of settlement. The highest ratio of shanty inhabitants are also in the settlements out 
of a municipality/town. Inhabitants of the shanty settlements add up to $21 \%$ of the total number of inhabitants living in this kind of settlement." (Slosar, 2009, s.492)

A big part of Roma population suffers from marginalization, poverty, exclusion and general refusal by the majority population. Throughout the last 2 decades their situation has significantly worsened in many countries. The environment for Roma children is characterized by isolation, poverty and exclusion. Bad housing conditions and bad infrastructure are even worsened by the regression of residential countries. Inhabitants of neglected quarters suffer from legal insecurity and often lack ownership rights, so their homes are not official and because of that they cannot register at their residence address. Due to this situation, basic services are inaccessible for them; practically "invisible", they live on the periphery of society where no one cares about them.

Education, of which level is influenced by residential segregation, aside from other thing, too, is very insufficient and limits access of Roma people to the labor market, and that leads to poverty and exclusion which most of the Roma people encounter nowadays. A lot of Roma people do not complete elementary education; only few of them finishes high school and a small minority obtains a university diploma.

While investigating the issue of early education of children from the marginalized Roma community, we have to become aware of two different approaches. On one hand, we speak about a different value system and cultural difference of Roma people which lead to the incapability of children to adapt to education system, and on the other hand, we mention social aspects of poverty to education which influence the failures of Roma people from marginalized communities.

An author mentioned below states that in the present day "it is not possible to definitely determine, which of the behavioral patterns in the community are the result of traditional lifestyle and which are the feature of poverty culture." (Necas, Ondrej Hala, 2010, s.493)

If we mention a different value system, it is manifested in different upbringing of children than the upbringing of the majority population. Prejudices like 'Roma people do not take care of their children' are not true. They take care of them, but differently. And the social difference is incompatible with the majority population. Roma people from socially disadvantaged environments are stimulated differently from an early childhood as a result of the neglected environment. That is why their intellect develops more slowly. Even though intellect itself does not determine success in school, it is important for persistence, diligence, emotional and social stability. Existence of segregated Roma schools is a sign of a more general problem, the existence of Roma 'ghettos'. Desegregation thus represents a problem not only for the school, but for the whole society. In many cases, the only kind of solution of the education situation is to firstly solve the situation in the Roma settlement villages. Desegregation, however, does not mean simply placing Roma and non-Roma children to one class. To break the vicious circle of exclusion it asks for an integrated long-term approach focused on making the people living in disadvantaged regions economically independent and increasing the quality of services. Unfortunately, many governments continually fail to adopt necessary measures.

Children have a basic right for equal, accessible help in developing their abilities and skills and for upbringing in family, regardless of region of a country or size of a settlement village. Childcare system's responsibility is to organize its services in a way it is equally accessible to all children, suitably to their age and needs. In many cases, development deficits of children are not discovered until beginning of school. This is huge disadvantage for children with special educational needs and their families.

When mentioning excluded settlements where people living in generational poverty are all concentrated in one place, we have particularly Roma inhabitants in mind. They fell to the deep poverty gap immediately by being born into the environment a fall deeper to the gap everyday. Without assistance of helping professions, they would have hardly make it out. Individuals and experts who help them in various problems, simultaneously become 'members' of their families, their lives. They gained trust with the empathetic attitude and build a bridge towards help and support with it.

At the beginning of the work, it is difficult to decide what to begin dealing with first, housing, employment rate, accessibility of drinking water, 
education, low financial literacy, health or unsuitable living conditions. Problems, mentioned above which they have to face every day and are the cause of exclusion, are present in every excluded community.

\section{Need for Early Care for Children in Roma Families}

The Roma community is specific in its own way and distinctive from the majority population. As was already mentioned, a fundamental pillar in upbringing of a Roma child and at the same time a central pillar in formation of child's personality is family. (Horňák, 2001) Socialization in Roma family:

- "upbringing is not individualistic, but collectivistic, it does not aim for bringing up an individual, but a member of wider family,

- everything is dealt with collectively, individual decisions are not recommended,

- 1st rule in a child's upbringing is its freedom,

- it is not expected of the child to make any effort while fulfilling school assignments,

- parents with the lowest education do not feel the need to change the way of living (instinctually, they see it as a problem of majority population) and they give their children just the same mindset,

- family protects the child, it is its sanctuary, but at the same time a border which cannot be overstepped,

- family hands the child in its Roma values, traditions, culture, philosophy of thinking and living, and that includes the rejection of way of thinking and living of the majority population." (Matulay, 1999, s.45)

When talking about a different value system, this is expressed mainly in a different way of bringing up children in comparison with the way of bringing up children in majority population. Director of Center of Research of Ethnicity and Culture, E. Kriglerová points out that traditional Roma family equals community upbringing. Within the community, socialization takes place through widespread family connections. That gives children a strong emotional base. Roma children are independent from an early age; they are brought up to be so. They learn communication, verbal and non-verbal, from adults. Children watch and observe them, listen to them, and learn values through that. She states, that children are brought up as little adults. (https://osf.sk/pribehy/ pribehy-eea/romske-deti-vdetskych-domovochtvoria-vacsinu-chybaju-podmienky-na-ichadaptaciu/).

While looking at old Roma family photos, we see mothers carrying their children tied to their bodies by scarfs in many pictures. It is obvious they were very close. Mothers were always prepared to feed and change their child. In the early phase of upbringing parents thought it is enough to satisfy the needs of children immediately.

Children develop in many ways and learn at a different rate, too.

M. Bartonova (2005) agrees that the environment in which a Roma child grows up is different in culture, language and set of values. In contrast with a majority children who grow up predominantly in nuclear families, Roma children grow up in a family with many relatives. Bartonova presents emotionality as an important fact. Children are often not given stimuli through books and painting tools. It results in insufficiently developing fine motor activity. Because they mostly think only about the present, motivation is another problem on the path to education. Other setbacks are the inability to concentrate and insufficient persistence.

As I. Radicova (2001) states, the approach of Roma people to education strongly depends on the type of family they come from. Parents from a marginalized Roma community and their children view education as an obligation towards the state, not their children. In settlements, where Roma people are integrated and are included in broader social network, their basic needs are satisfied and differentiated perception of poverty, education itself gains in value.

We cannot omit the fact that every child who comes from stimuli-deficient environments needs a specific, individual approach from teachers, tutors and other professionals. New trends, approaches and methods of education based on the principle of humanism and understanding of cultural, ethnical, social and educational specifics have to be used. Only if all the principles are followed, signs of trust from the members of the Roma community can be expected. This will be expressed in the effort and willingness to participate, and thus fulfill mutual societal goals; increasing the quality of pre-elementary and elementary education of Roma children. Actually 
we have to be aware that without proper cooperation of Roma people, all the effort would be useless, and by that the misunderstanding between the minority and majority population would be deepened.

Nowadays, the environment of segregated localities and generationally reproduced poverty is a precondition of negative development of early childcare. It is important to deal with the socioeconomical situation of a community as a whole; but it is also important to focus on prevention, education and support for families with children.

In many cases, we can talk about parental failure, their insufficient EQ or emotional perception of the child's situation, lack of interest or pathological negligence of the child. But we can equally proceed from total poverty of parents, influence of socio-pathological behavior, psychological or mental characteristics of individuals. Social control and surveillance, activation of family and community, and mobilization of socio-legal protection of the child and organs focused on its protection are part of the protective factors in the situation. When an appropriate combination of intervention for the wellbeing of the child, internal and external motivation, support service and individualistic approach is used, it is possible to overcome the deficiencies and risks on the parental side even though it is hard target.

\section{References}

1. BARTONOVA M (2005) Current trends in the education of children and pupils with special educational needs in the Czech Republic. Brno: MSD, 2005, 416 p. ISBN 80-86633-3732.

2. MATULAY S (2007) Terminological reflection on the adjectives social and societal,a. 2007. In: Healthcare and social work - ISSN 1336-9326.

3. NECAS S, ONDREJ J, HALA M (2010) Social, Economic, Legal and Security Issues of the Present; Private University of Economic Studies, Prague, 2010, ISBN: 978-80-8674484-1.

4. RADICOVA I (2001) Hic Sunt Romales. Bratislava: Foundation S: P: A: C: E:, 2001, p. 64.

5. SLOSAR D 2009. Drugs and drug addiction. In: Drug prevention in social work: a collection of papers from the international scientific conference and conference of young scientists "Drugs and related socio-pathological phenomena and the weight of social work", held on 20.11.2009 in Košice. Košice: KSK, UPJŠ, FF, KSP. ISBN 978-80-970251-8.

6. ACT NO. 245/2008 Coll. on Upbringing and Education (School Act) and on Amendments to Certain Acts.

7. HORNAKOVA K (2006) Early intervention in Slovakia. Bratislava: Institute of Children's Speech, Bratislava - lectures from the 10th. International Conference of the Slovak Speech Therapists Association. 2006. [online]. [cited 2010-03-16].

8. KNEZOVICOVA Z (2010) How the Early Intervention Program Works in the USA. [online]. [cited 2010-03-16]. Available at: http // www.radost.sk/kniznica.php?show=more...7 ...5. 